|| Print ISSN: 2589-7837 || Online ISSN: 2581-3935 ||

International Journal of Medical Science and Diagnosis Research (IJMSDR)

Available Online at www.ijmsdr.com

NLM (National Library of Medicine ID: 101738824)

Review Article

Volume 5, Issue 10; October:2021; Page No. 08-14

\title{
Comparison between the Effectiveness of Kinesio Taping and Stretching Exercise in Contemporary Dancers with Chronic Shin Splints
}

\section{Rashmi Honey}

Post-Graduate Student, Department of Physiotherapy, Guru Nanak Dev University, Amritsar-143005, Punjab, India

\section{Conflicts of Interest: Nil}

Corresponding author: Rashmi Honey

DOI: https://doi.org/10.32553/ijmsdr.v5i10.864

\begin{abstract}
:
The purpose of the present study was to compare the effectiveness of kinesio taping and stretching exercises in contemporary dancers with chronic shin splints. In the present study, purposively review the published evidence regarding risk factor associated with chronic shin splints in contemporary dancers, assess the effectiveness of kinesio taping, and stretching exercises, of the 45 citations identified, we emphasised results of the nine reports that compare the effect of kinesio taping method to prevent shin splints, twenty-three reports on the effect of shin splints in contemporary dancers, seventeen reports the effect of stretching exercises in shin splints, and two reports the effect of both kinesis taping and stretching exercises on contemporary dancers with repetitive stress and overused activities. The result of the kinesio taping and stretching exercises programs in contemporary dancers with chronic shin splints have undergone assessment of controlled trials. There is no strong support for any of these interventions, and each of four control trials is limited methodologically. The most encouraging evidence for effective prevention of chronic shin splints involves the use of stretching exercise programs. However, serious flaws in study design and implementation constraints the work in this field thus far.
\end{abstract}

Keywords: Kinesio taping technique, Stretching exercise program, Chronic Shin Splints, Contemporary dancers.

\section{Introduction:}

Shin splint, a nonspecific term to describe exertion of all leg pain, is one of the most common problems of athletes ${ }^{(1)}$ ballet dancers, and military recruits $^{[2]}$. Groups that are commonly affected include runners, dancers, military personnel ${ }^{[3]}$. The condition is characterised by pain along the postero-medial aspect of the distal two-third of the tibia that occurs before, during, or after activity ${ }^{[4]}$. Shin soreness, shin splints syndrome, medial tibial stress syndrome (MTSS), and soleus syndrome are the other terms that have been used to describe this exercise-included pain syndrome ${ }^{[s]}$.

\section{Definition of Shin Splints}

Shin splints are the most common cause of painful shin ${ }^{[\varpi]}$. These are two regions where you can suffer shin splints:(1) Anterior Shin Splints -It is located on the front (or anterior) part of the shin bone and involves the tibialis anterior muscles. The tibialis anterior lifts and lowers your foot. It lifts your foot during the swing phase of a stride. Then, it slowly lowers your foot to prepare your foot for the support phase. If your anterior shin pain increases when lifting your toes up while keeping heels on the ground you are likely to suffer from anterior shin splints. Medically anterior shin splints can also be referred to as anterior tibialis stress syndrome(ATSS). (2) Posterior tibialis stress syndrome is located on the inside rear (or medial/posterior) part of the shin bone and involves the tibialis posterior muscle. The tibialis lifts and controls the medial aspect of your foot 
arch during the weight bearing support phase. When your tibialis posterior is weak or lacks endurance your arch collapses (over pronates), which creates torsional shin bone stresses. If you feel pain along the inside rear of your shin boneyou are likely to suffer from either posterior shin splints or tibia stress fracture. Medically, posterior shin splints and tibial stress fracture can also be referred to as medial stress syndrome (MTSS).

\section{Methods of Minimising Shin Splints}

At present, there is no universally accepted consensus on either the ethology or treatment of this condition ${ }^{[]}$. The treatment of shin splints focuses on providing symptomatic relief and modifying the risk factor.In clinic practise, the use of various modalities to treat symptoms is common ${ }^{[]}$. The acute pain associated with shin splints is treated with the RICE (Rest,Ice, Compression and Elevation) regimen.The use of manual therapy techniques such as digital ischemic pressure ,transverse friction massage, and sustained myofascial tension has also been advocated $^{[8]}$. Besides, non-steroidal anti inflammatory drugs, iontophoresis, phonophoresis, ice massage ${ }^{[1[9]}$, ultrasound ["], low energy laser treatment ${ }^{[1[1] 1]}$, periosteal pecking[ ${ }^{[1]}$, stretching and strengthening exercises sports compression stocking ${ }^{[12]}$, and pulsed electromagnetic ${ }^{[]]}$field have been investigated,but it remains unclear which treatment is most effective ${ }^{[13[1[1]}$.

\section{Movements causing Shin Splints}

Classical ballet movement and jump landings require ankle range of motion and stability when balancing in extreme single leg stance postures ${ }^{[15[1[16]}$. Sufficient ankle plantar-flexion is vital to achieving full pointe and postural control is important to technical execution and the elegance of movement associated with ballet ${ }^{[1]}$. The primary purpose of this study is to prevent injuries caused while jumping or landing. It is claimed that,when applied with appropriate tension, KT lifts the fascia and soft tissue and produces additional space below the area of application which is said to enhance clearance of extra fluid of edge a and bleeding by improving circulation and normalise muscle function by realigning input ${ }^{[183 .}$ These effects are postulated to be about immediate reduction of pain and improved athletic performance ${ }^{[10]}$.

\section{Kinesio Taping Procedure}

The study consisted of 3 days on 30 active sports persons afflicted with shin splint $(\mathrm{M}=22, \mathrm{~F}=8$; mean age $19+/-2.59$; duration of symptoms $48.16+/-13.42$ days) assigned randomly into three equal groups. The intervention in the control group consisted of 10 minutes of ice massage followed by 10 minutes of transcutaneous electrical nerve stimulation. In the KT group, Y-strip k-tape was applied to the lower leg using the technique ${ }^{[19]}$. Griebert et al. In 2016 ${ }^{[15]}$ reported that application of KT decreased the rate of medial plantar loading among patients with a history of MTSS and suggested that application of K-tape may prove beneficial in relieving symptoms of shin splint ${ }^{[8]}$. The investigator could not locate any study that examined the use of KT in shin splints. Keeping this in consideration, this pilot study was designed to have preliminary evidence about the effectiveness of KT in shin splints. The specific research questions were (a) does the addition of KT to conventional symptomatic Physiotherapy modalities benefit the dancers afflicted with shin splints in terms of reducing discomfort and improving performance and (b) can the similar benefits be achieved by application of stretching exercise.

\section{Causes of Dance related Injury}

This assumption was supported by (lawson. 1991) $)^{[9]}$, (Galbraith et al., 2009) ${ }^{[20]}$ who in an articulations in the Dancing Times, found the 'lower leg' to be the most common self-reported injury (although shin splint were not provided as an option for the reported data, which would have been useful). This article in the Dancing Times highlighted the epidermis of shin splints ${ }^{[9]}$ and how it will be often evident in dancers who will be instructed to force their feet to 180 degree ,regardless of the available external rotation at the hip ${ }^{[2]}$ Lawson (Galbraith et al., 2009) ${ }^{[20]}$ suggested that this problem was exerted when dancers perform on flat, rather than raked, floors . 
The majority of the literature that discussed the incidence of injuries among dancers attributed them to a lack of injuries among dancers attributed them to a lack of anatomical turnout and compensation to achieve optimal turnout [13][2][23]. Other possible causes of injury are hyper-mobility ,hypo-mobility, and lack of strength ${ }^{[24]}$. A sudden increase in intensity of frequency in activity level fatigues muscles too quickly to properly help shock absorption, forcing the tibia to absorb most of the impact.

This stress is associated with the onset of shin splints $^{[25]}$. Muscle imbalance, including weak core muscles, inflexibility and tightness of Lower leg muscles, including the gastrocnemius, soleus , and plantar muscles, tibialis anterior, soleus muscle, extensor digitorum longus, extensor hallucinate longus, flexor digitorum brevis, tibialis posterior, peroneus tertius, and peroneus longus ${ }^{[26}$ (commonly the flexor digitorum longus) can increase the possibility of shin splints[s]. The pain associated with shin splints is caused by a disruption of Sharpey's fibers that connect the medial soleus fascia through the periosteum of the tibia where it inserts into the bone ${ }^{[25]}$. With repetitive stress, the act forces eccentrically fatigue the soleus and create repeated tibial bending or bowing, contributing to shin splints. The impact is made worse by running uphill, downhill, on uneven terrain, or on hard surfaces. Improper footwear, including worn -out shoes, can also contribute to shin splints ${ }^{[23][24]}$.

\section{Discussion}

In the present study, we found the effects of Kinesio taping (KT) and stretching exercises in contemporary dancers with chronic splints. The study carried out with twenty-two chronic shin splints common, eight studies with the effect of Kinesio tape(KT) on shin splints, seventeen studies with stretching exercises on shin splints, three with comparison between the effectiveness of Kinesio taping and stretching exercises in contemporary dancers with Chronic Shin Splints. In this study, we found that there is no significant difference between Kinesio tape(KT) and stretching exercises in contemporary dancers with
Chronic Shin Splints. Both groups are effective in treating chronic shin splints.

However, we found that Shin splints are common in contemporary dancers. Several studies have been designed to investigate the effect of Kinesio taping(KT) and stretching exercises individually. As a popular treatment for several health conditions with acute shin splints ${ }^{[19]}$. Some studies showed no significant changes in shin splint treatment, few of those studies reported no outcome measure. For the patient -reported parameters i.e, pain at rest, pain at $50 \mathrm{~m}$ sprint, the main effects were significant for the time but not for groups. Where as some of the studies Kachanathu et al. (2018) ${ }^{[2]}$ showed that the both groups benefited from the intervention but the response to Kinesio tape was better than that of orthotics and some studies Athanasiadis et al. (2019) ${ }^{[28]}$ showed that there is further need to investigate the effectiveness of taping methods on ankle proprioception in a population with ankle musculoskeletal injuries and pathology.

Whereas few of those studies reported some benefits of Kinesio tape(KT) on improving the shin splints. Gribert et al. (2016) ${ }^{[15]}$ did a study on Kinesio tape(KT) reduces rate of loading in participants with medial tibial stress syndrome (MTSS) and reported that Kinesio tape(KT) decreases the rate of medial loading in patient with medial tibial stress syndrome (MTSS) ${ }^{[15]}$. Aline et al. (2019) ${ }^{[28]}$ did a study on Kinesio taping on ankle complex motion and stiffness and jumping time to stabilisation in female ballet dancers and reported that the pairwise comparison showed Kinesio tape (KT) significantly restricted inversion rotation compared to no taping(NT) $(\mathrm{p}=0.0002)$ and Static taping $(\mathrm{ST})(\mathrm{p}<0.001)$. In addition, the Kinesio taping (KT) supports significantly restricted eversion rotation compared to Non taping(NT) ( $\mathrm{p}=0.007)$ and static taping (ST) $(\mathrm{p}=0.05)$. However, there is no significant difference between static taping (ST) and no taping(NT) were found for either inversion rotation $(p=0.072)$ or eversion rotation $(\mathrm{p}=0.239)$. Berezutsky et al. $2018^{[29]}$ did a study on possibilities of Kinesio taping to prevent injuries of professional dancers and reported that Kinesio taping $(\mathrm{KT})$ has broad 
utility in primary and secondary prevention of dance -related to injuries.

Previous study done by Kaufman et al. (2020) ${ }^{\text {sol }}$ to assess the forced or compensated turnout lead to musculoskeletal injuries in dancers and concluded that injury prevalence in dancers is high, and misaligned turnout (TO) is claimed to bear injury risk. Jo Baker et al. (2010) ${ }^{(s)}$ done to assess self reported and reported injury patterns in contemporary dance students and concluded that the incidence of injuries of first-year dance students at this conservation was high and may be due to the sudden increase in workload with fulltime training.

Sekulic et al. (2020) ${ }^{\text {во }}$ done study previously to assess the higher risk for injury was evidenced in older and more experienced dancers. Whereas, 57 dancers $(47 \%)$ reported no musculoskeletal injury/ problem, (43\%) 57 dancers reported a musculoskeletal problem, and (10\%) 13 dancers reported a musculoskeletal injury. When across dance styles, no significant differences were obtained. A prevalence of $39 \%$, multiple injuries /problems was reported and $10 \%$ of dancers. A higher volume of training, even in the youth dancers, in order to prevent injury, special attention should be placed on more experienced dancers and investigation showed that dynamic balance is a more important predictor of injury occurrence than age.

Kenny et al. (2012) $)^{(3) 1}$ studied previously to assess the injury burden in professional ballet and contemporary dancers and concluded that the timeloss and medical attention injury definitions underestimate the injury burden in professional dancers. Cymet et al. (2006) ${ }^{[33}$ assess the shin splints painful to have and to treat and concluded that causes is often obvious relationship to overloading exercise or activity and the pain and rule out stress fracture and other causes of pain , while treatment slow is effective. Rest, ice, NSAIDs, and gradual increase in training intensity have been shown to reduce the incidence of shin splints. EZY et al. (2020) ${ }^{[s+1}$ the overwhelming majority of dancers face injuries throughout their careers. The effect of injuries can range from resting for two weeks to Carter ending and to guide young and collegiate dancers who are interested in injury prevention and want to take initiative steps.

Few studies reported some lack of high quality studies, consequences regarding risk factor for musculoskeletal injury in professional remains difficultiso and some study was assess whether dancers exhibit injuries profile and patterns of injuries related coping behaviour as a function of passion, it appear that obsessive passion for dance may constitute a risk factor for sustaining chronic injuries, and that harmonious passion is the more optimal motivational foundation for long term, healthful involvement in dance.

Shah et al. (2012) $)^{[3]}$ did study on injuries in professional modern dancer incidence, risk factors, and management and concluded that these professional modern dancers suffer from a rate of injury similar to other groups of professional dancers whereas most dancers return to a partial level of dancing several weeks before attempting full capacity dancing.

Johnston et al. (2006) ${ }^{[4]}$ conducted a study on a randomised controlled trial of a leg orthosis versus traditional treatment for soldiers with shin splints and reported that there was no significant difference because of the small sample size, high dropout rate, small effect size and resultant low power. Despite multiple months collecting data , researchers were unable to obtain enough subjects to detect the meaningful difference. The use of iontophoresis and phonophoresis, Lower leg braces versus no braces, no significant differences for either lower leg braces was found and concluded that , after examination of all treatment extracorporeal shockwave therapy (ESWT) appears to be the most promising ${ }^{[3]}$. Core stabilisation training was performed after and before evaluation of physical fitness parameters included vertical jump performance, flexibility, dynamic balance, coordination, proprioception, muscle and hip flexion is isokinetic strength measure and concluded that improvement of joints reposition, and jump performance in universities level pre-professional dancers and after 8 weeks with core stabilisation exercises (CTS) program ${ }^{[3 s .}$. 
Stretching and strengthening exercises, orthotics, ice, rest and patient counselling appear to be the best management strategy for shin splints. Once the patient's pain has decreased by $25 \%$ the stretching and exercise program is performed bilaterally like towel stretch, standing calf stretch, anterior compartment stretch, resisted dorsiflexion, heel raises, standing toe raises, static and dynamic balance exercises ${ }^{[39]}$.

On the other hand, the medial tibial stress syndrome showed no current evidence supporting any single prevention methods and concluded that most promising outcomes support the use of shock-absorbing insoles. Well designed and controlled trials are critically needed to decrease the incidence of this common injury ${ }^{[3]}$ whereas there is no significance difference in age, duration of symptoms, or pain measure between the 2 groups at baseline, and no changes in any of outcome measure in post treatment testing, but significant between groups differences were identified of pain during activity, change score for pain during activities, change score in pressure thread hold, and change in EHL: EDB ratios and concluded that the study was therapeutic intervention focused on restoring muscle balance appear to be effective ${ }^{[40]}$.

Tekin et al. (2018) $)^{[1]}$ conducted a study on balancing training in modern dancers proprioceptive neuromuscular training versus Kinesio taping. The present study found that 8 weeks of additional proprioceptive neuromuscular ( PN) training exercises significantly increase that static and dynamic balance performance and concluded that the Kinesio taping (KT) application with a mechanical correction technique on the left ankle joint of the supporting leg may significantly increases semi dynamic and dynamic balance performance. On the other hand, Beirami et al. (2020) ${ }^{[42]}$ assess the study on the effect of 6 weeks static stretching and Kinesio taping on hamstring shortness in soccer players and concluded that the both group of effects are almost equals on hamstring shortness and knee joints range of motion and can be use to corrective therapeutic methods for such injuries.

\section{Acknowledgements}

The author is thankful and whole-heartedly expresses gratitude towards the author of Journals/ books/ Articles mentioned in the references which proved a great value to this research.

\section{Conflicts of interest}

There are no conflicts of interest.

\section{Reference}

1. Leanderson, J., Eriksson, E., Nilsson, C. and Wykman, A., 1996. Proprioception in Classical Ballet Dancers. The American Journal of Sports Medicine, 24(3), pp.370374.

2. Bates P. Shin splints--a literature review. Br J Sports Med. 1985 Sep; 19(3):132-7. doi: 10.1136/bjsm.19.3.132.

3. Bionic ballerinas. The Lancet. 1985; 326(8453):481-2.

4. Johnston, E., Flynn, T., Bean, M., Breton, M., Scherer, M., Dreitzler, G., \& Thomas, D. (2006). A randomized controlled trial of a leg orthosis versus traditional treatment for soldiers with Shin Splints: A pilot study. Military Medicine, 171(1), 40-44.

5. Mooney, V. (2013). Clinical Orthopaedic Rehabilitation, 2nd ed., Steven B. Brotzman, $\mathrm{MD}$, and Kevin Wilk, PT, Mosby/Elsevier, 2003. The Spine Journal, 4(3), 523-525.

6. Miller M, Hart J, MacKnight J. Essential orthopaedics. 2nd ed. Elsivier; 2017. p. 657661.Mien, M. H., Rayer, S., Schipper, M., Schmikli, S., Weir, A., Tol, J. L., and Backx, F. J. (2011). Shockwave treatment for medial tibial stress syndrome in athletes; a prospective controlled study. British Journal of Sports Medicine, 46(4), 253-257.

7. Crisp, T., 2008. Clinical review of sports medicine. : 3rd ed. Eds P Brukner, K Khan. (A\$ 108.99.) Sydney: McGraw-Hill, 2001. ISBN 0-074-70651-9. Tata McGraw-Hill Publishing Company Ltd., 35(5), pp.567-569.

8. Lawson, \& John, R. (1991). The shin splints epidemic. The Dancing Times, 137.

9. Parreira, P. do, Costa, L. da, Takahashi, R., Junior, L. C., Junior, M. A., Silva, T. M., \& Costa, L. O. (2014). Kinesio taping to generate 
skin convolutions is not better than Sham taping for people with chronic non-specific low back pain: A randomised trial. Journal of Physiotherapy, 60(2), 90-96.

10. Nissen, L., Astvad, K., \& Madsen, L. (1994, January 1). [Low-energy laser therapy in medial tibial stress syndrome]: Semantic scholar. undefined. Retrieved October 2, 2021,

from https://www.semanticscholar.org/paper/ $\% 5$ BLow-energy-laser-therapy-in-medialtibial-stress-Nissen-

$\underline{\text { Astvad/75185d478a42e69c31aa7ac547fac8d }}$ $\underline{615 \mathrm{~b} 494 \mathrm{ff}}$

11. Robertson, M. (2012, January 1). [PDF] the relative effectiveness of periosteal pecking combined with therapeutic ultrasound compared to therapeutic ultrasound in the treatment of medial tibial stress syndrome type II: Semantic scholar. Undefined. Retrieved October 2, 2021, from https://www.semanticscholar.org/paper/ The-relative-effectiveness-of-periostealpecking-to-

Robertson/5db96378f1091aec38173bdbbbe7 ecf3d3af85eb

12. Bauman, P., Singson, R. and Hamilton, W., 1994. Femoral Neck Anteversion in Ballerinas. Clinical Orthopaedics and Related Research, \&NA; (302), pp.57???63.

13. Reinking, M. F. (2007). Exercise-related leg pain: a review of the literature. The American Journal of Sports Medicine, 34(9), 170-178.

14. Griebert, M. C., Needle, A. R., McConnell, J., \& Kaminski, T. W. (2016). Lower-leg kinesio tape reduces rate of loading in participants with medial tibial stress syndrome. Physical Therapy in Sport, 18, 62-67.

15. Moen, M. H., Bongers, T., Bakker, E., Weir, A., Zimmermann, W., van der Werve, M., \& Backx, F. (2010). The additional value of a pneumatic leg brace in the treatment of recruits with medial tibial stress syndrome; a randomized study. Journal of the Royal Army Medical Corps, 156(4), 236-240.

16. Ahonen J. Biomechanics of the foot in dance: a literature review. J Dance Med Sci. 2008; 12(3):99-108.
17. Kese, K., Wallis, J. and Kase, T., 2003. Kase, K., Wallis, J. and Kase, T. (2003) Clinical Therapeutic Applications of the Kinesio Taping\&reg Method. 2nd Edition, Kinesio Taping Association, Dallas, 12. - References Scientific Research Publishing. [online] Scirp.org.Available at: $<$ https://www.scirp.org/(S(351jmbntvnsjt1 aadkposzje))/reference/referencespapers.aspx ?referenceid $=2292632>$ [Accessed 1 October 2021].

18. Sinha, A. G. K., \& Sharma, U. (2017). Comparison of effectiveness of Kinesio taping with nonelastic taping and no taping in players with acute shin splints. Physiotherapy - The Journal of Indian Association of Physiotherapists, 11(1), 21.

19. Galbraith, R. M., \& Lavallee, M. E. (2009). Medial tibial stress syndrome: Conservative treatment options. Current Reviews in Musculoskeletal Medicine, 2(3), 127-133

20. Coplan, J. A. (2002). Ballet dancer's turnout and its relationship to self-reported injury. Journal of Orthopaedic \& Sports Physical Therapy, 32(11), 579-584.

21. Reid, D. C. (1988). Prevention of hip and knee injuries in ballet dancers. Sports Medicine, 6(5), 295-307.

22. Khan, K., Brown, J., Way, S., Vass, N., Crichton, K., Alexander, R., Baxter, A., Butler, M., \& Wark, J. (1995). Overuse injuries in classical ballet. Sports Medicine, 19(5), 341-357

23. Lobby \& MacKenzie. (2014, September 9). Running 101: How to select the best pair of Running shoes. Shin splints WikiProjectMed. Retrieved October 2, 2021, from https://mdwiki.org/wiki/Shin splints.

24. Brinkman MJ, Buist I, Bredeweg SW. (2012) The treatment effect of pulsed electromagnetic field in sports atheletes with medial tibial stress syndrome; a pilot study. Geneeskunde en Sport ,3:12-9

25. Craig, D. I. (2008). Medial tibial stress syndrome: Evidence-based

prevention. Journal of Athletic Training, 43(3), 316-318. 
26. Kachanathu, S. J., Algarni, F. S., Nuhmani, S., Alenazi, A. M., Hafez, A. R., \& Algarni, A. D. (2018). Functional outcomes of Kinesio taping versus standard orthotics in the management of Shin Splint. The Journal of Sports Medicine and Physical Fitness, 58(11).

27. Botsis AE, Schwarz NA, Harper ME, Liu W, Rooney CA, Gurchiek LR, Kovaleski JE. Effect of Kinesio ${ }^{\circledast}$ Taping on Ankle Complex Motion and Stiffness and Jump Landing Time to Stabilization in Female Ballet Dancers. J Funct Morphol Kinesiol. 2019 Apr 8; 4(2):19.

28. Vladimir Berezutsky. (2018). Possibilities of kinesio taping to prevent injuries of professional dancers. International Journal of Occupational Safety and Ergonomics, 25(4), 638-645.

29. Kenny, S. J., Whittaker, J. L., \& Emery, C. A. (2015). Risk factors for musculoskeletal injury in Preprofessional dancers: A systematic review. British Journal of Sports Medicine, 50(16), 997-1003.

30. Sekulic D, Prus D, Zevrnja A, Peric M, Zaletel P. Predicting injury status in adolescent dancers involved in different dance styles: A prospective study. Children. 2020; 7(12):297.

31. Cimelli SN, Curran SA. Influence of turnout on foot posture and its relationship to overuse musculoskeletal injury in professional contemporary dancers. Journal of the American Podiatric Medical Association. 2012; 102(1):25-33.

32. Jo Baker, MSc, Daniel Scott, MSc, Katherine Watkins, MCSP, Sheramy Keegan-Turcotte, MSc, Matthew Wyon, M., 2010. SelfReported and Reported Injury Patterns in Contemporary Dance Students. Medical Problems of Performing Artists, 25(1), pp.1015.

33. Sekulic D, Prus D, Zevrnja A, Peric M, Zaletel P. Predicting injury status in adolescent dancers involved in different dance styles: A prospective study. Children. 2020;7(12):297.

34. Story, J., \& Cymet, T. C. (2006). Shin splints: Painful to have and to treat. Comprehensive Therapy, 32(3), 192-195.
35. Batenhorst, E. Z. Y. (2020). A dancer's view: Analysis and Prevention of Common Dance Injuries. Digital Commons@WOU. Retrieved October 2021, from https://digitalcommons.wou.edu/honors theses/225/

36. Weiss, D. s, J, R., \& Burchette. (2012). Injuries in Professional modern Dancers incidence, risk Factor and Management . Journal of Dance Medicine and Science, 16(1).

37. Rompe JD, Cacchio A, Furia JP, Maffulli N. Low-energy extracorporeal shock wave therapy as a treatment for medial tibial stress syndrome. The American Journal of Sports Medicine. 2009; 38(1):125-32.

38. Kalaycioglu, T., Apostolopoulos, N. C., Goldere, S., Duger, T., \& Baltaci, G. (2020). Effect of a core stabilization training program on performance of ballet and modern dancers. Journal of Strength and Conditioning Research, 34(4), 1166-1175.

39. Nautche. (2005, January 1). Rehabilitation and Prevention of Shin Splints: A systematic review of literature.: Semantic scholar. undefined. Retrieved October 2, 2021, from https://www.semanticscholar.org/paper/ The-prevention-of-shin-splints-insports\%3A-a-review-ThackerGilchrist/21a7f356085b6e806690f8c60dad36 d5a1896aea?p2df.

40. Newsham, K. R., Beekley, M. D., \& Lauber, C. A. (2012). A neuromuscular intervention for exercise-related medial leg pain. Journal of Sport Rehabilitation, 21(1), 54-62.

41. Tekin, D., Agopyan, A., \& Baltaci, G. (2018). Balance training in modern dancers: Proprioceptive-neuromuscular training vs Kinesio taping. Medical Problems of Performing Artists, 33(3), 156-165.

42. Beirami, N. P., Kazani, A., Roohi, B. N.-, Skrypchenko, I., Joksimović, M., \& Gardašević, N. (n.d.). The effect of 6 weeks static stretching and kinesiotaping. Retrieved October 2, 2021, from https://oapub.org/edu/index.php/ejep/art icle/download $/ 3382 / 6018$ 